This is the final peer-reviewed accepted manuscript of:

Luca Guardigli, Marco A. Bragadin, Francesco Della Fornace, Cecilia Mazzoli, Davide Prati, Energy retrofit alternatives and cost-optimal analysis for large public housing stocks, Energy and Buildings, Volume 166, 2018, Pages 48-59.

The final published version is available online at: https://doi.org/10.1016/i.enbuild.2018.02.003

Rights / License:

The terms and conditions for the reuse of this version of the manuscript are specified in the publishing policy. For all terms of use and more information see the publisher's website. 


\title{
Energy retrofit alternatives and cost-optimal analysis for large public housing
}

\section{stocks}

\author{
Luca Guardiglia1, Marco A. Bragadina, Francesco Della Fornace ${ }^{a}$, Cecilia Mazzolia, Davide Pratia \\ a University of Bologna, DA - Department of Architecture, Viale del Risorgimento 2, Bologna 40136, Italy
}

\begin{abstract}
( $\max 200$ words)
The study of cost effective solutions for the energy retrofitting of existing buildings is of capital importance for building asset owners, since high up-front investments are required and long payback times are encountered in building renovation projects. The aim of the work is to propose a decision support system (DSS) for the assessment of different renovation strategies through the measure of their economic sustainability in relation to the achieved energy efficiency. The cost optimal analysis of energy retrofit alternatives is performed in the case of a large housing stock owned by a semi-public real estate company, with the goal of meeting nearly zero energy building standards. Energy performances as well as related energy and construction costs are analysed for different retrofit options, adopting Italian laws and regulations. The proposed DSS evaluates the economic sustainability of various design alternatives with the net present value (NPV) and the global cost (GC), as suggested by the EPBD recast EU directive. These indicators are finally compared with the building energy performance index (EP), providing the most efficient design alternatives for each building typology and the most advantageous renovation project among the considered ones.
\end{abstract}

Keywords: cost optimal analysis, economic sustainability, housing stock, energy retrofit, payback period, global cost, net present value, energy performance index, decision support system, design alternatives.

Notes:

- All the figures in print should be coloured for a clear understanding of the diagrams.

- All the images and diagrams have been produced by the authors.

- This research did not receive any specific grant from funding agencies in the public, commercial, or notfor-profit sectors.

\footnotetext{
${ }^{1}$ Corresponding author. Postal address: Viale del Risorgimento 2, Bologna 40136, Italy

E-mail address: luca.guardigli@unibo. it
} 


\section{Introduction}

Cost effective solutions for energy retrofitting projects are of capital importance for owners, especially for public or semi-public real estate companies who are dealing with large housing stocks [1, 2]. Planning strategies and a cost/benefit analysis should be accurately developed [3], especially in the case of deep renovation projects with the goal of meeting nearly zero energy buildings (nZEBs) requirements $[4,5]$.

State-owned real estate companies usually hold a large amount of built assets and may have the need of a reliable decision support system (DSS) for the selection of the most cost-effective energy retrofitting projects. The aim of the present research work is to make a proposal for a DSS to help identifying the optimal intervention strategy for the energy retrofitting of public housing stocks. The proposed system entails a methodology that consists in analysing different design options for some selected buildings and, subsequently, in evaluating both energy performances and costs, in order to identify a cost-optimal design alternative.

All the considered energy retrofit interventions should be technically feasible and economically, ecologically and socially sustainable. In most cases they end up being successful only when special social, technical and economic conditions take place at the same time, creating a favourable situation. In the residential sector key aspects are usually represented by unacceptable living conditions caused by structurally deficient or unhealthy buildings and unsafe social conditions. Favourable situations are encouraged by public policies, stimulating reduced interest rates and promoting direct support, or tax discounts.

Environmental and economic aspects of sustainability are always present at the same time, bringing up various issues in relation to the viable evaluation criteria $[6,7]$. The present study focuses on economic sustainability, analysing some widely applied retrofitting technologies. Economic sustainability implies the use of strategies [8] to optimize existing resources in such a way that a responsible and beneficial balance can be achieved over the longer term. Within a business context, economic sustainability involves using the assorted assets of the company efficiently to allow it to continue functioning profitability over time. Unfortunately, considering intervention costs, the practice of the last 20 years has proven that the only two relevant economic parameters in the evaluation of the potentiality of building renovation are the initial costs (IC) and the payback period (PBP). Above all, the latter one is usually expected to be very short, eventually shorter than 10 years, and in any case much shorter than the economic life of the newly installed or replaced elements. It is well known that such a short PBP is rarely feasible, and only under certain very profitable circumstances, 
such as the application of the Directive 2001/77/CE on the promotion of electricity produced from renewable energy (in Italy the "Conto Energia" i.e. Energy Account). Nevertheless, in the case of considerably large public housing stocks the search for a cost optimal solution in a long-term perspective is of major importance in the definition of a building retrofitting strategy for multiple deep renovation projects. Therefore, the goal of the research work is to provide energy managers with some tools to compare a set of potential renovations [9] for their IC, PBP and global cost (GC) in relation to the energy performance of the building. The results will give new and fast insights on the economic and related environmental sustainability of energy retrofit alternatives in a life cycle perspective. Furthermore, they will help to quickly understand the impact of the solutions on the achievement of nZEB standards, in order to find the most suitable intervention strategies.

\section{The cost optimal approach}

\subsection{The cost-optimal approach of the Directive 2010/31/EU EPBD recast}

With regard to the economic sustainability of building refurbishments during the life cycle, the Directive 2010/31/EU has introduced the life cycle cost analysis (LCCA) in the European legislation, with the aim of evaluating the energy performance in relation to a series of costs [10]. The cost optimal approach, or "global cost method", has the goal of establishing a comparative methodology framework for calculating cost optimal levels of minimum energy performance requirements of building and building elements, valuable for new construction and refurbishment projects. LCCA can be applied to the construction and the operation phase, with the aim of minimizing energy cost and consumption during lifespan.

The GC analysis can be performed at financial level, with no substantial differences between the EU approach and existing standards concerning LCC [11], but if the analysis is performed at a macroeconomic level the EU regulation 244/2012 (with the guidelines of the accompanying document 2012/C 115/01) adds the category "cost of greenhouse gas emission" [12]. Therefore, in the macroeconomic calculation the GC includes the cost of greenhouse gas emissions over the study period. In the former case, the perspective is clearly the one of the owner, or entrepreneur, in the latter the social costs are considered and possibly included in tax policies. Models that provide a holistic view of the life cycle energy and greenhouse gas emissions of housing stocks do not exist in literature, as mentioned by some researchers of the Dublin Institute of Technology [13]. However, it is thought that macroeconomic analysis should be introduced in renovation programs of public real estates, in order to lead to a more ethical decision making. Greenhouse emissions 
are internationally related to the Global Warming Potential unit [14], the Carbon dioxide equivalent $\left(\mathrm{CO}_{2} \mathrm{e}\right)$, calculated over a time interval of 20,100 or 500 years. The GWP of $\mathrm{CO}_{2}$ is standardized to 1 and the GWP of the other elements is derived from this value. Methane, for instance, has a lifetime of 12.4 years and with climate-carbon feedbacks a GWP of 86 over 20 years and 34 over 100 years in response to emissions.

The European Commission delegate Regulation n. 244/2012 defines the GC as the sum of the present value of the initial investment costs, sum of running costs, and replacement costs (referred to the starting year), as well as disposal costs. A basic reference for the definition of GC is the European standard EN 15459, which follows the concept of Life-Cycle analysis, as addressed by pertinent literature [15]. The regulation indicates the following cost categories for the GC evaluation: initial investment, energy, operational, maintenance, replacement, disposal, greenhouse emissions. The GC (financial calculation) of a design alternative can be calculated with the following:

$G C(\tau)=C i+\sum_{j}\left[\sum_{i=1}^{\tau}(C a, i(j) \times R d(i))-V f, \tau(j)\right]$ 'O(

Where: $\tau$ is the calculation period; GC(T) is the global cost over the calculation period, referred to the starting year; $\mathrm{Ci}$ is the initial investment cost for the element $j ; \mathrm{Ca}, i(j)$ is the annual cost during year $i$ for the element $j$; $V f, r$ is the residual value of the element $j ; R d(i)$ is the discount factor for year $i$ based on discount rate $r$ to be calculated. The discount rate can be calculated with the following formula:

$\operatorname{Rd}(p)=\left(\frac{1}{1+\frac{r}{100}}\right)^{p}$ '1(

Where: $p$ is the number of years from the starting period; $r$ is the real discount rate.

The cost-optimal approach of the EU directive is based on the present value of the projection in the future of construction costs, running costs and disposal costs of the design alternative studied. The advantage of this method is to be related to a calculation period in which energy performances of building system and subsystems can be compared considering the final value of the sub-system (e.g. electric energy or HVAC system) that have a lifespan longer than the calculation period. Given that, the GC analysis follows a comparative methodology: invariant elements of different alternative design solutions, which do not influence system costs or system performance, can be omitted. The purpose of the European regulation was not to define a performance-based comparative calculation method, which indeed has been already established by international standards, but to identify reference buildings for each Member State, divided into building categories (single-family buildings, apartment blocks and multifamily buildings, office buildings, commercial buildings) with specific energy performance requirements. Besides all, an evaluation system of energy performance 
has been introduced, and it can be very useful in the design phase to detect the most efficient design alternative. Therefore, overlooking the main goal of the methodology indicated by the European legislation, designers, owners and project managers could use this method to perform an accurate analysis of costs and performances of building systems and sub-systems to aid the design process in the selection of a better alternative for a building project. Public managers, indeed, should take into consideration environmental aspects of interventions.

With the aim of completing the global cost analysis of the selected interventions, the net present value (NPV) of the cash flow of each design alternative can be computed. The NPV is another measure of the profitability of an undertaking that is calculated by subtracting the present values of cash outflows (including initial cost) from the present values of cash inflows over a period. Incoming and outgoing cash flows can also be described as benefit and cost cash flows, respectively.

$N P V(\tau)=\sum_{i=1}^{\tau}(C F, i \times R d(i))$

Where: $r$ is the calculation period; $N P V(T)$ is the net present value over the calculation period, referred to the starting year; $C F, i$ is the cash-flow (benefit minus costs) during year $i$; $R d(i)$ is the discount factor for year $i$ based on discount rate $r$ to be calculated with eq. (2).

If the inflation rate of energy has to be considered, the discount factor is the following:

$R d f(p)=\left(\frac{1+\frac{f}{100}}{1+\frac{r}{100}}\right)^{p}$

Where: $p$ is the number of years from the starting period; $r$ is the real discount rate; and $f$ the real inflation rate of energy.

The discount cash-flow method allows to obtain the NPV of initial costs $(C I)$ and energy costs $(C e)$ over a certain study period.

$N \operatorname{PVpbp}(\tau)=C i+\sum_{i=1}^{\tau}(C e, i \times R d f(i))$

Where: $\tau$ is the calculation period; $\operatorname{NPVpbp}(\tau)$ is the NPV over the PBP period, referred to the starting year and including the initial cost: $\mathrm{Ci}$ is the initial investment cost for the element $j$; $\mathrm{Ce}, i$ is the energy annual cost during year $i$; $R d f(i)$ is the discount factor for year $i$ based on discount rate $r$ and inflation rate $f$ to be calculated from eq. (5). The Pay Back Period (PBP) can be found setting eq. (5) to zero. The equations (1) and (5) have been used to evaluate costs and energy performances in the suggested design support system (DSS). 


\subsection{Previous work}

The cost optimal approach for the evaluation of design alternatives has been proposed by standards and regulations [16] and it is widely present in scientific literature, especially with regard to residential buildings [17]. Hamdy, Hasan and Siren search for cost optimal building solutions in line with the EPBD- recast 2010 with a sophisticated procedure [18]; building solutions are investigated for dwellings in Finland aiming at nZEB targets. Objective functions of the proposed cost-optimisation approach are the primary energy consumption function and the difference in life cycle cost (LCC) between any design option and the reference design. Optimal combinations of building envelope, heat-recovery design options, heating/cooling systems and renewable energy sources are found. Although focused only on new residential buildings in a specific climate zone, the study investigates in depth the cost-optimal approach for the evaluation of a big variety of building solutions. Preferable cost-optimal integrations of energy saving measures and renewable energy sources options are specifically given at different energy price escalation rates.

With regard to this issue, Ruparathna, Hewage and Sadiq [19] make a proposal for a novel LCCA approach which allows to calculate LCC by adopting the fuzzy set theory. A case study was conducted for a public building operated in Canada. The use of the fuzzy-based approach would enable the forecasting of possible future LCC because of changes in macro-economic factors. The proposed approach tries to eliminate several criticisms associated with current LCCA methods: errors in judgement of future conditions, service life, optimistic estimates, future maintenance activities, changes in predicted inflation rates, material and labour costs, etc. The fuzzy-based method applied to this case study reveals that it is possible to achieve higher LCC savings. A similar approach is followed by Di Giuseppe, Massi and D'Orazio [20], using a probabilistic approach to find the uncertainties in LCCA. Although changes on macro-economic factors are of vital importance in GC calculation, according to the authors the technical aspects of design alternatives and the characteristics of the buildings still play a major role in defining the optimal strategy for energy rehabilitation projects with nZEB targets.

The cost optimal approach is applied to different building typologies in different climates. Congedo, D'Agostino, Baglivo, Tornese and Zacà [21] emphasize the potential energy improvement that the costoptimal analysis is able to provide in energy retrofitting projects with respect to the baseline scenarios. The results illustrate the suitability of the EPBD recast methodology to assess cost-optimality and energy efficien- 
cy in school building refurbishment. The research indicates different design alternatives to provide the most cost-effective balance between costs and energy saving. Some calculations are performed for residential buildings in another research by the same group [22]. Pikas, Thalfeldt and Kurnitsky [23] suggest a costoptimal approach to achieve zero-energy-building solutions for office buildings. Building solutions are found for fenestration design in the cold Estonian climate with the NPV approach. A window-wall cost ratio analysis is performed, depending on insulation thickness, and the impact of window costs on NPV calculations are discussed related to the target of reaching nZEBs levels. The same cost-optimal approach to achieve nZebs targets for residential buildings is followed by Kurnitski et al., according to REHVA definitions [24]. Residential buildings and nZEBs targets are also taken into consideration by Ferreira, Almeida and Rodrigues [25]. The results indicate that the transition from the cost-optimality to nZEB may occur without major efforts, being possible to integrate both concepts with nZEB being reached by adding renewable energy systems to the cost-optimal levels of the buildings' envelope, giving support to the nZEB definition presented in the current thermal regulations. However, it is worth reminding that in the most used nZEB definitions the perspective of building life cycle is not considered.

\section{DSS approach and case studies selection}

If the scientific literature highlights the variation of optimization values for different building characteristics and energy systems, the common practice of building refurbishment proves that most interventions end up with initial and operational costs that are not expected at the beginning. This is due to the fact that theoretical assumptions are usually not followed by the correct execution of renovation works. For this reason, the development of a DSS for the assessment of different renovation strategies for a large housing company should start from the implementation of a robust and accurate assets database, collecting all the necessary data for reliable energy calculations (fig. 1). The archive should lead to a selected and limited number of potential buildings for their actual poor energy performances and/or high maintenance costs. For this set of buildings it should be possible to carry out a second phase of inspection and survey, in order to check the existing data and have a clear overview of the potential investments and the functional goals that the decision makers would like to achieve. In fact, as long as the final decisions must be taken on the basis of a good knowledge of the building, the preliminary phase of survey and inspection is essential. On site investigations are of vital importance to avoid frequent unrealistic data that can lead to wrong energy and cost calculations $[26,27]$. 
Following this phase, it is possible to identify a number of design alternatives, including the installation of renewable sources systems, whose costs are accurately determined on the basis of previous interventions. For reasons of simplification, only the deep (or major) renovations are taken into consideration, excluding the very common minor renovations on small parts of the building or single components of the HVAC system with little influence on the overall behaviour of the construction. According to Italian regulations, the so-called major renovations embrace all the elements and components of the envelope containing the volume at a controlled temperature, with a minimum impact of $25 \%$ on the total external surface (S) of the building [28].

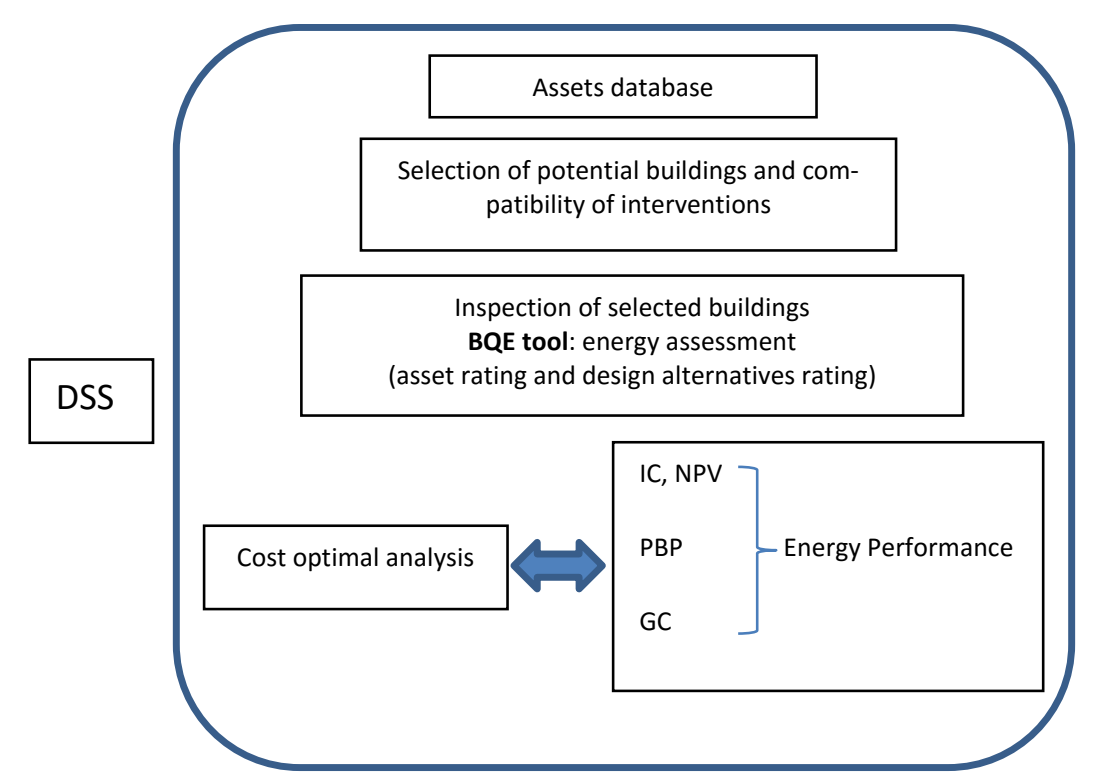

Fig. 1. Scheme of DSS with different phases of analysis.

The potential interventions should match 5 fundamental criteria, according to the proposed DSS scheme:

- effectiveness, in accordance with the conservation of the artistic an contextual values of the building and other dimensional constraints;

- economic sustainability of the initial investment;

- environmental sustainability, in the broadest sense, assessed on the basis of thermo-physical criteria aimed at maximizing efficiency, minimizing consumption and avoiding the intensive use of renewable energy sources;

- adaptability, assessed on the basis of a customized design process aimed at integrating the technologies in the specific building context;

- compatibility with service operations, in order to facilitate the asset monitoring and maintenance and ensure the continuity of energy supply and thermal comfort. 
It is quite evident that the combination of design alternatives is theoretically infinite. However, it is also true that the market of building components offers a set of retrofit alternatives that is consolidated, and decision makers tend concentrate on solutions that are commonly used in practice. Therefore, if the initial data are correctly inserted, it is rather quick to identify a fair number of feasible technical solutions.

For energy and cost calculations all the required data of the DSS are implemented into a novel tool called BQE (Building Quality Evaluator), which can produce the requested results [29]. Given a set of potential interventions and a number of selected buildings, for each alternative it is possible to assess the following outputs: initial costs, payback period, net present value, global cost, $\mathrm{CO}_{2}$ emissions and related energy performance indexes (winter and summer) for the whole building. These data can be obviously matched with nZEB targets. The proposed DSS calculations follow the Italian regulations, but the procedure can be easily adapted to any other European context.

For the purpose of our research, we processed a significant amount of data concerning more than $50 \%$ of the 664 housing units of the public company for personal services called "ASP - Città di Bologna", creating a first database on building envelopes, building services and maintenance costs. A lot of information came from original construction documents.

Major objectives of the company are the organization and the provision of welfare and integrated social and health services in favour of the elderly. After a first selection of buildings for their potential renovation, three case studies were selected for presentation in this paper. In particular, the analysed buildings are three multi-function complexes called Services Centres, that offer different housing options depending on the degree of autonomy of the residents: a house residence for seniors, a day centre addressed to senior citizens and users with dementia, apartments dedicated to a nursing home for elderly people and apartments for independent individuals or couples. The case studies presented in this research work regard multi-function buildings, but in terms of typology they can be easily associated to residential buildings.
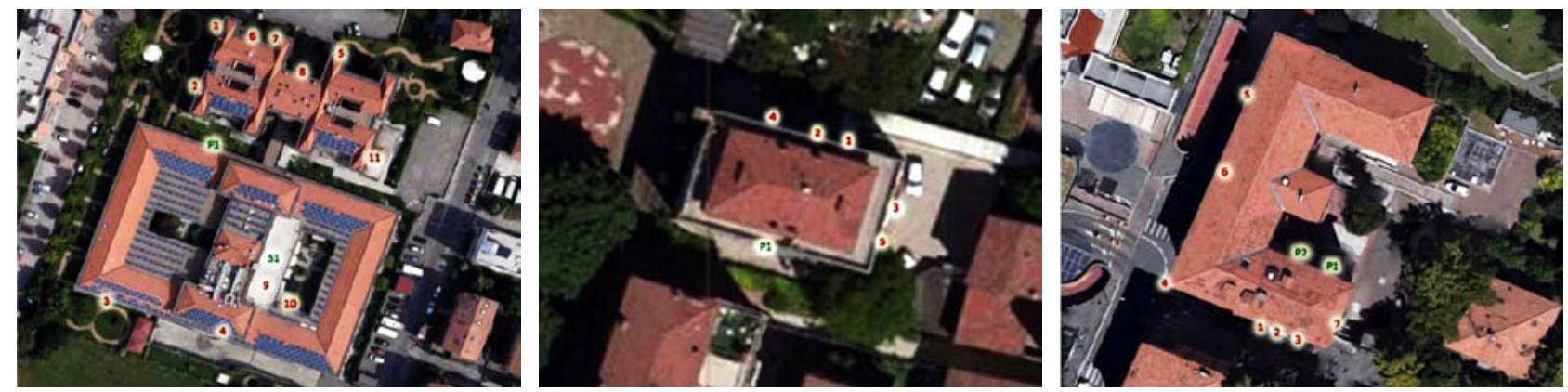

Fig. 2. Buildings No. 1, No. 2 and No. 3: aerial view and points of investigation. 

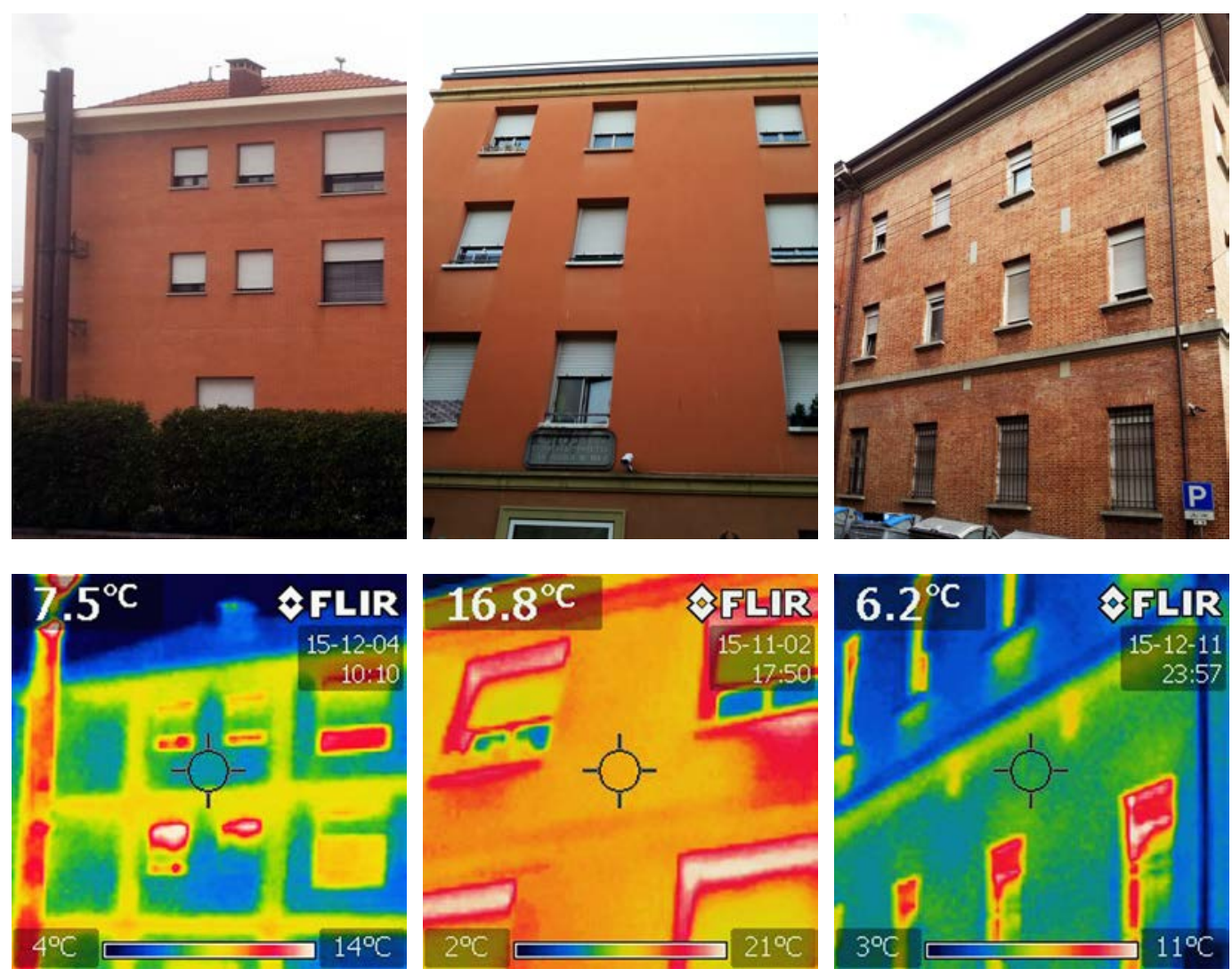

Fig. 3. a) Building No. 1 "Lercaro" Service Centre; b) Building No.2 "San Nicolò di Mira" Service Centre;

c) Building No.3 "Albertoni" Service Centre.

The three buildings were selected for their typological (technological and morphological) variety (fig. 2). The building No. 1, named "Lercaro" Service Centre, is placed inside a former apartment building that was built between 1992 and 2001 with good thermal performances (approximatively 50\% lower than the actual standard). On the contrary, the building No. 2, named "San Nicolò di Mira" Service Centre, was built in 1960 with very poor thermal characteristics (100\% lower than actual standards). The building No. 3, named "Albertoni" Service Centre, is a traditional construction, placed inside an historical open courtyard building; built before 1920, this architecture is protected for its historical and artistic values. While the first two complexes were built with a reinforced concrete structure, the third one is a masonry construction (fig. 3). The facades of building No. 2 are characterized by hollow bricks walls and single glazed windows, with a little attention to heat transmission; on the contrary, the facades of building No. 1 are sealed with fire-clay blocks and pay more attention to details and thermal bridges corrections. The main thermal and geometrical features of the buildings are implemented in the DSS and summarized in table 1. Many instrumental diagnostic surveys were carried out in 2015 and 2016, using thermographic images and thermal flow-meter measurements to control the quality of the available information (fig. 4). 

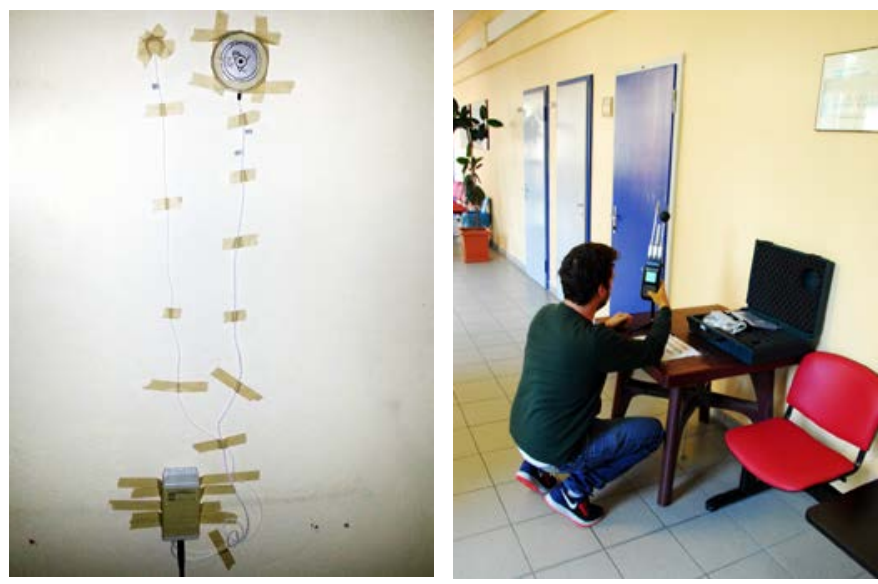

Fig. 4. On site investigations on selected buildings for renovation.

The three selected case studies are located in the metropolitan area of Bologna, which belongs to zone $\mathrm{E}$ of the Italian climatic classification. Since 4271 municipalities belong to this zone, which is the biggest in Italy, the buildings can be considered a significant sample of the national housing stock. This climatic zone, with its 2100-3000 DegreeDays over the winter season, is representative of many other European areas with a continental climate.

\begin{tabular}{|c|c|c|c|c|c|c|c|c|}
\hline \multirow{4}{*}{ Case Studies } & \multirow{2}{*}{$\begin{array}{c}\text { Gross Volume } \\
\text { (V) }\end{array}$} & \multirow{2}{*}{ Net Floor Area } & \multirow{2}{*}{ S/V } & \multicolumn{4}{|c|}{ Thermal transmittance (U-value) } & \multirow{2}{*}{$\begin{array}{c}\text { Energy per- } \\
\text { formance } \\
\text { index }\end{array}$} \\
\hline & & & & walls & windows & roof & ground & \\
\hline & $V_{1}$ & $A_{n f}$ & $S / V_{1}$ & $\mathrm{U}_{\mathrm{p}}$ & $\mathrm{U}_{\mathrm{w}}$ & $\mathrm{U}_{\mathrm{r}}$ & $\mathrm{U}_{\mathrm{g}}$ & $E P_{H}$ \\
\hline & $\mathrm{m}^{3}$ & $\mathrm{~m}^{2}$ & $\mathrm{~m}^{-1}$ & $\mathrm{~W} / \mathrm{m}^{2} \mathrm{~K}$ & $\mathrm{~W} / \mathrm{m}^{2} \mathrm{~K}$ & $\mathrm{~W} / \mathrm{m}^{2} \mathrm{~K}$ & $\mathrm{~W} / \mathrm{m}^{2} \mathrm{~K}$ & $\mathrm{kWh} / \mathrm{m}^{2} \mathrm{y}$ \\
\hline $\begin{array}{l}\text { Building No. } 1 \\
\text { "Lercaro" }\end{array}$ & $30,198.70$ & $9,885.50$ & 0.59 & 0.571 & 2.850 & 0.588 & 0.572 & 114.30 \\
\hline $\begin{array}{l}\text { Building No. } 2 \\
\text { "San Nicolò di } \\
\text { Mira" } \\
\end{array}$ & 2972.40 & 931.00 & 0.49 & 1.798 & $3.350 / 4.200$ & 1.311 & 0.312 & 189.66 \\
\hline $\begin{array}{l}\text { Building No. } 3 \\
\text { "Albertoni" }\end{array}$ & $10,449.70$ & 2920.10 & 0.48 & $1.113 / 1.519$ & 1.950 & 1.800 & 1.610 & 255.95 \\
\hline
\end{tabular}

Table 1. Case studies: thermal and geometrical data. $\mathrm{S}$ is the external surface of the buildings.

\section{Cost optimal analysis and discussion}

A set of different building renovation alternatives, both for the related energy performances (evaluated adopting the quasi-steady-state calculation method, from national and local regulations, primarily ISO 13790 and UNI-TS 11300 series) [30, 31], and for their cost (evaluated adopting the real prices of recently accomplished building renovation projects by the same company in the same area) were analysed.

For the selected buildings energy running costs are derived from national databases and converted into primary energy costs. The economic sustainability of the different options was evaluated in the DSS through different matching parameters. The NPV of initial costs and running energy costs was computed with the 
equation (1), and (3) of section 2.1. The energy-performance-evaluator tool BQE (Building Quality Evaluator) performed energy calculations for the buildings (asset rating), giving all the required data. The energy performance indices (EP) for space heating and cooling, hot water and equipment running were calculated according to the UNI-TS 11300 series, following the Italian decrees 192/2005 and 311/2006 and the last decree of June $26^{\text {th }} 2015[32,33]$, which establishes the requirements for the reference building in order to meet near Zero Energy targets [34]. The selected design alternatives are reported in the following table 2.

\begin{tabular}{|c|c|c|}
\hline$n^{\circ}$ & description of interventions & combinations of interventions \\
\hline 1 & - thermal insulation of facades (EPS, internal and/or external, $10 \mathrm{~cm}$ ) & 1 \\
\hline 2 & - thermal insulation of facades (Rockwool, internal and/or external, $10 \mathrm{~cm}$ ) & 2 \\
\hline 3 & • thermal insulation of entire envelope (EPS) & 3 \\
\hline 4 & - thermal insulation of entire envelope (Rockwool) & 4 \\
\hline 5 & • windows replacement & 5 \\
\hline 6 & - condensing boiler replacement & 6 \\
\hline 7 & - photovoltaic system (1 kWp/unit) & 7 \\
\hline 8 & $\begin{array}{l}\text { - thermal insulation of facades (EPS, internal and/or external, } 10 \mathrm{~cm} \text { ) } \\
\text { - windows replacement }\end{array}$ & $1+5$ \\
\hline 9 & $\begin{array}{l}\text { - thermal insulation of facades (Rockwool, internal and/or external, } 10 \mathrm{~cm} \text { ) } \\
\text { - windows replacement }\end{array}$ & $2+5$ \\
\hline 10 & $\begin{array}{l}\text { - thermal insulation of entire envelope (EPS) } \\
\text { • windows replacement }\end{array}$ & $3+5$ \\
\hline 11 & $\begin{array}{l}\text { - thermal insulation of entire envelope (Rockwool) } \\
\text { - windows replacement }\end{array}$ & $4+5$ \\
\hline 12 & $\begin{array}{l}\text { - thermal insulation of entire envelope (EPS) } \\
\text { - windows replacement } \\
\text { - condensing boiler replacement }\end{array}$ & $3+5+6$ \\
\hline 13 & $\begin{array}{l}\text { - thermal insulation of entire envelope (Rockwool) } \\
\text { - windows replacement } \\
\text { - condensing boiler replacement }\end{array}$ & $4+5+6$ \\
\hline
\end{tabular}

Table 2. Selected design alternatives and their combinations.

The cost efficiency of the selected interventions for each of the case studies was assessed by calculating three cost optimal parameters: the NPV of the cash flow between energy costs and savings (referred to the initial situation and over a 30 years period) (eq. 3), the PBP including initial cost and energy costs (eq. 5), and the GC for a study period of 10, 20 and 30 years (eq. 1).

The alternatives have been computed with the following assumptions:

a) the considered real discount rate $r$ is $3.1 \%$ and the inflation rate of energy cost is 3.3\%, (source: Italian Authority of electricity and gas);

b) the quantity of energy saved each year is equal over all the investment period;

c) the national tax relief (e.g. economic incentives), given for refurbishment works is not considered. Incentives are equal to a tax relief of $65 \%$ of retrofitting value in accordance with the Italian law.

All the results of calculations are reported in the following tables 3,4 , and 5 . Costs of design alternatives are referred to the complete work, including finishes and scaffoldings. Boxes are coloured in red when GC fol- 
lowing any of the interventions is bigger than GC without intervention (row 0), and in green when GC with intervention is smaller than GC without intervention.

\begin{tabular}{|c|c|c|c|c|c|c|c|c|c|c|c|}
\hline$n^{\circ}$ & $\begin{array}{l}\text { Intervention } \\
\text { Area }\end{array}$ & $\begin{array}{l}\text { Intervention } \\
\text { Cost }\end{array}$ & $\begin{array}{c}I I C u= \\
\operatorname{Cost} / A_{n f}\end{array}$ & $E P_{H}$ & $\begin{array}{l}\text { Annual } \\
\text { Savings }\end{array}$ & PBP & $\begin{array}{c}\text { Energy } \\
\text { first } \\
\text { year } \\
\text { cost }\end{array}$ & NPV & GC 10 & GC 20 & GC 30 \\
\hline & $m^{2}$ & $€$ & $€ / m^{2}$ & $\mathrm{kWh} / \mathrm{m}^{2} \mathrm{y}$ & $€ / m^{2}$ & years & $€$ & $€$ & $€$ & $€$ & $€$ \\
\hline 0 & 0 & 0 & 0 & 114,3 & 0,00 & - & 96.850 & - & 946.098 & 1.907 .909 & 2.885 .692 \\
\hline 1 & 4153 & 332.320 & 34 & 104,45 & 0,78 & $>30$ & 88.503 & -124.105 & 1.196 .887 & 2.075 .811 & 2.969 .332 \\
\hline 2 & 4154 & 353.090 & 36 & 104,66 & 0,76 & $>30$ & 88.681 & -108.112 & 1.219 .395 & 2.100 .087 & 2.995 .404 \\
\hline 3 & 17334 & 1.110 .165 & 112 & 77,19 & 2,87 & $>30$ & 65.405 & -265.074 & 1.749 .092 & 2.398 .629 & 3.058 .954 \\
\hline 4 & 17334 & 1.196 .845 & 121 & 77,66 & 2,82 & $>30$ & 65.803 & -364.872 & 1.839 .662 & 2.493 .155 & 3.157 .500 \\
\hline 5 & 1248 & 374.700 & 38 & 104,82 & 0,70 & $>30$ & 88.817 & -168.728 & 1.242 .329 & 2.124 .367 & 3.021 .053 \\
\hline 6 & - & 103.950 & 11 & 107,58 & 0,67 & 16 & 91.156 & 92.636 & 994.425 & 1.899 .688 & 2.819 .984 \\
\hline 7 & 200 & 120.000 & 12 & 114,3 & 0,33 & $>30$ & 96.850 & -24.142 & 1.066 .098 & 2.027 .909 & 3.005 .692 \\
\hline 8 & 5401 & 707.020 & $72^{*}$ & 95 & 1,47 & $>30$ & 80.496 & -273.013 & 1.493 .366 & 2.292.771 & 3.105 .451 \\
\hline 9 & 5401 & 727.790 & $74^{*}$ & 95,21 & 1,46 & $>30$ & 80.674 & -298.502 & 1.515 .874 & 2.317 .046 & 3.131 .523 \\
\hline 10 & 18585 & 1.484 .865 & $150^{*}$ & 67,9 & 3,53 & $>30$ & 57.534 & -444.495 & 2.046 .896 & 2.618 .260 & 3.199 .112 \\
\hline 11 & 18585 & 1.571 .545 & $159^{*}$ & 68,48 & 3,49 & $>30$ & 58.025 & -543.664 & 2.138 .376 & 2.714 .621 & 3.300 .435 \\
\hline 12 & 18585 & 1.588 .815 & $161^{*}$ & 64,67 & 3,92 & $>30$ & 54.797 & -434.721 & 2.124 .110 & 2.668.294 & 3.221 .516 \\
\hline 13 & 18585 & 1.675 .495 & $169 *$ & 65,36 & 3,86 & $>30$ & 55.381 & -539.675 & 2.216 .501 & 2.766 .492 & 3.325 .616 \\
\hline
\end{tabular}

Table 3. Building No. 1 "Lercaro" - Alternatives to interventions and results for PBP, NPV and GC. * Mean value of interventions with different costs.

\begin{tabular}{|c|c|c|c|c|c|c|c|c|c|c|c|}
\hline$n^{\circ}$ & $\begin{array}{l}\text { Intervention } \\
\text { Area }\end{array}$ & $\begin{array}{l}\text { Intervention } \\
\text { Cost }\end{array}$ & $\begin{array}{c}I I C u= \\
\operatorname{Cost} / A_{n f}\end{array}$ & $E P_{H}$ & $\begin{array}{l}\text { Annual } \\
\text { Savings }\end{array}$ & PBP & $\begin{array}{c}\text { Energy } \\
\text { first } \\
\text { year } \\
\text { cost }\end{array}$ & NPV & GC 10 & GC 20 & GC 30 \\
\hline & $m^{2}$ & $€$ & $€ / m^{2}$ & $\mathrm{kWh} / \mathrm{m}^{2} \mathrm{y}$ & $€ / m^{2}$ & years & $€$ & $€$ & $€$ & $€$ & $€$ \\
\hline 0 & 0 & 0 & 0 & 190 & 0,00 & - & 15.135 & - & 147.849 & 298.153 & 450.953 \\
\hline 1 & 814 & 65.120 & 70 & 95 & 7,46 & 9,6 & 7.589 & 141.904 & 139.255 & 214.621 & 291.238 \\
\hline 2 & 814 & 69.190 & 74 & 96 & 7,41 & 10,3 & 7.640 & 136.447 & 143.824 & 219.697 & 296.830 \\
\hline 3 & 1192 & 88.790 & 95 & 82 & 8,72 & 11,2 & 6.506 & 153.005 & 152.346 & 216.958 & 282.643 \\
\hline 4 & 1192 & 94.750 & 102 & 82 & 8,65 & 12 & 6.569 & 145.322 & 158.922 & 224.160 & 290.481 \\
\hline 5 & 108 & 32.400 & 35 & 178 & 0,86 & $>30$ & 14.243 & -8.507 & 171.533 & 312.977 & 456.770 \\
\hline 6 & - & 12.375 & 13 & 182 & 0,64 & 21,1 & 14.541 & 5.309 & 154.424 & 298.832 & 445.638 \\
\hline 7 & 48 & 36.000 & 39 & 190 & 1,30 & $>30$ & 15.135 & -35 & 183.849 & 334.153 & 486.953 \\
\hline 8 & 922 & 97.520 & $105^{\star}$ & 84 & 8,26 & 13 & 6.711 & 131.580 & 163.080 & 229.728 & 297.484 \\
\hline 9 & 922 & 101.590 & $109^{*}$ & 85 & 8,21 & 13,6 & 6.773 & 126.149 & 167.750 & 235.009 & 303.385 \\
\hline 10 & 1300 & 121.190 & $130^{*}$ & 71 & 9,50 & 14 & 5.648 & 142.190 & 176.366 & 232.459 & 289.483 \\
\hline 11 & 1300 & 127.150 & $137^{*}$ & 72 & 9,43 & 14,8 & 5.710 & 134.549 & 182.934 & 239.645 & 297.297 \\
\hline 12 & 1300 & 133.565 & $143^{*}$ & 68 & 9,73 & 15 & 5.426 & 136.415 & 186.574 & 240.464 & 295.248 \\
\hline 13 & 1300 & 139.525 & $150^{*}$ & 69 & 9,67 & 15,8 & 5.487 & 128.847 & 193.127 & 247.618 & 303.015 \\
\hline
\end{tabular}

Table 4. Building No. 2 "San Nicolò di Mira" - Alternatives to interventions and results for PBP, NPV and GC. . * Mean value of interventions with different costs. 


\begin{tabular}{|c|c|c|c|c|c|c|c|c|c|c|c|}
\hline$n^{\circ}$ & $\begin{array}{c}\text { Intervention } \\
\text { Area }\end{array}$ & $\begin{array}{l}\text { Intervention } \\
\text { Cost }\end{array}$ & $\begin{array}{c}I I C u= \\
\text { Cost/ } / A_{n f}\end{array}$ & $E P_{H}$ & $\begin{array}{l}\text { Annual } \\
\text { Savings }\end{array}$ & PBP & $\begin{array}{c}\text { Energy } \\
\text { first } \\
\text { year } \\
\text { cost }\end{array}$ & NPV & GC 10 & GC 20 & GC 30 \\
\hline & $\mathrm{m}^{2}$ & $€$ & $€ / m^{2}$ & $\mathrm{kWh} / \mathrm{m}^{2} \mathrm{y}$ & $€ / m^{2}$ & years & $€$ & $€$ & $€$ & $€$ & $€$ \\
\hline 0 & 0 & 0 & 0 & 255,95 & 0,00 & - & 64.063 & - & 625.813 & 1.262 .019 & 1.908 .791 \\
\hline 1 & 2859 & 157.245 & 54 & 170,35 & 7,28 & 7,6 & 42.638 & 476.138 & 573.761 & 997.194 & 1.427 .659 \\
\hline 2 & 2859 & 171.540 & 59 & 171,17 & 7,21 & 8,3 & 42.843 & 455.978 & 590.061 & 1.015 .532 & 1.448 .070 \\
\hline 3 & 4753 & 280.893 & 96 & 110,84 & 12,27 & 8 & 27.743 & 786.565 & 551.904 & 827.415 & 1.107 .501 \\
\hline 4 & 4753 & 301.670 & 103 & 112,06 & 12,17 & 8,7 & 28.048 & 757.119 & 575.664 & 854.207 & 1.137 .377 \\
\hline 5 & 325 & 97.500 & 33 & 253,81 & 0,39 & $>30$ & 63.527 & -63.897 & 718.081 & 1.348 .968 & 1.990 .331 \\
\hline 6 & - & 49.500 & 17 & 230,37 & 2,53 & 6,9 & 57.660 & 171.017 & 660.769 & 1.233.391 & 1.815 .524 \\
\hline 7 & 480 & 315.000 & 108 & 255,95 & 3,93 & 27,7 & 64.063 & 26.998 & 940.813 & 1.577 .019 & 2.223 .791 \\
\hline 8 & 3184 & 254.745 & 87 & 168,22 & 7,45 & 12 & 42.105 & 393.316 & 666.053 & 1.084.192 & 1.509 .274 \\
\hline 9 & 3184 & 269.040 & 92 & 169,04 & 7,38 & 12,7 & 42.310 & 373.160 & 682.353 & 1.102 .530 & 1.529 .685 \\
\hline 10 & 5078 & 378.393 & 130 & 108,75 & 12,43 & 10,7 & 27.220 & 702.900 & 644.293 & 914.609 & 1.189 .415 \\
\hline 11 & 5078 & 399.170 & 137 & 109,97 & 12,33 & 11,3 & 27.525 & 673.505 & 668.053 & 941.402 & 1.219 .290 \\
\hline 12 & 5078 & 439.845 & 151 & 95,88 & 13,70 & 11,2 & 23.998 & 752.209 & 674.277 & 912.603 & 1.154 .886 \\
\hline 13 & 5078 & 453.650 & 155 & 96,96 & 13,61 & 11,7 & 24.269 & 730.862 & 690.723 & 931.733 & 1.176 .746 \\
\hline
\end{tabular}

Table 5. Building No. 3 "Albertoni" - Alternatives to interventions and results for PBP, NPV and GC .

The energy performance index for space heating $\left(E P_{H}\right)$ is reported for each intervention, together with the annual savings and the payback period (PBP). A PBP of more than ten years brings no advantage for the selected alternative, because the study period turns out to be longer than the service life of the new building components. The most attractive alternative for decision makers is obviously the one with the lowest PBP. Then, NPV and GC of each intervention can be found in the last four columns of each table. As previously described, a colour code (green vs red) was used to indicate the design alternatives that increase the economic performances in comparison with the situation before renovation. For example, the most advantageous alternative for building "Lercaro" is the number 6 (condensing boiler replacement) with a PBP of 16 years, which coincides with a convenient GC evaluation on a 30 years study period. The PBP values for all the other interventions are greater than thirty years (table 3 ).

The analysis of building No. 2, "San Nicolò di Mira", indicates that the PBP of almost every design alternative is shorter than 30 years; even the GC analysis indicates that almost all alternatives offer better solutions than the situation before renovation. Nevertheless, PBP and GC values indicate different advantageous solutions, since for PBP the best intervention is the number 1, "EPS thermal insulation of Facades", while for GC the best is intervention is number 3, "EPS thermal insulation of entire envelope" (table 4). Even the analysis of building No. 3 indicates that the PBP of almost every design alternative is shorter than 30 years (often less 
than 20 years), and the GC analysis indicates that almost all alternatives offer better solutions than the situation before renovation. As regards the case of building No. 2, the calculations indicate the alternative number 1, "EPS thermal insulation of Facades", for having the shortest PBP and the alternative 3, "EPS thermal insulation of entire envelope" for having the smallest GC (table 5).

Not surprisingly, the combinations of interventions give better results over the long period, regardless their initial cost. On the contrary, GC calculations over a 10 years period, which is considered a persuasive time perspective for a renovation strategy, do not show encouraging results. As a consequence, public incentives are strongly required to activate renovation projects with a satisfactory GC.

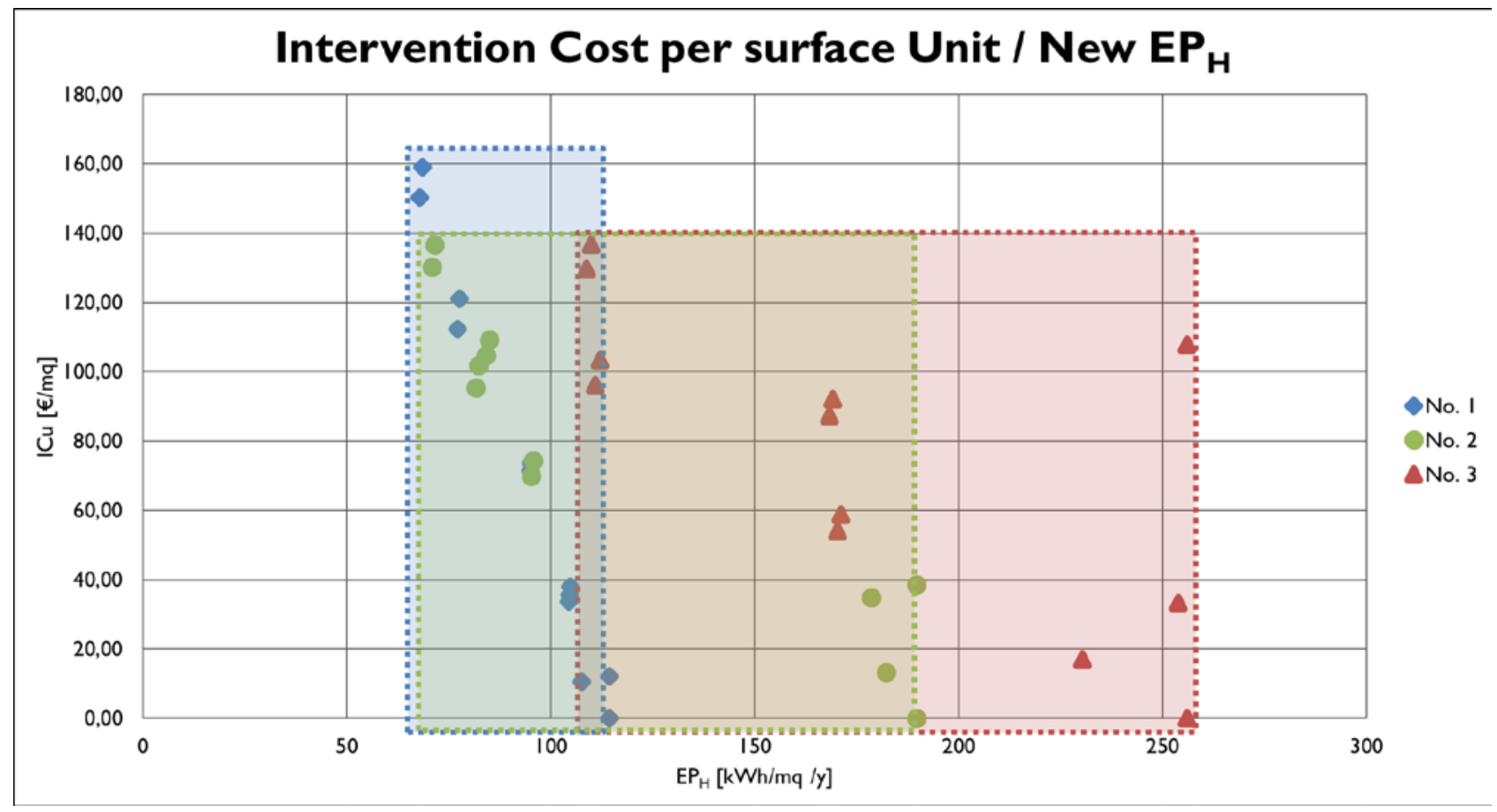

Fig. 5. Interventions and their combination, with related Intervention Cost per surface Unit (ICu) and energy performance index for space heating $\left(E P_{H}\right)$.

An in-deep understanding of the performed cost-optimal analysis can be achieved in the DSS by plotting the outputs on a Pareto-optimal space (fig. 5), where the initial costs are divided by the intervention surface of the buildings $\left(€ / \mathrm{m}^{2}\right)$, plotted on the y-axis and termed Intervention Cost per surface Unit (ICu), as computed in tables 3, 4 and 5. On the $x$-axis the annual demand of primary energy for space heating per square meter $\left(E P_{H}\right)$, or energy performance index, expressed in $\mathrm{kWh} / \mathrm{m}^{2} \mathrm{y}$, is plotted. The energy performance indices for water heating $\left(E P_{\mathrm{W}}\right)$, ventilation $\left(E P_{\mathrm{V}}\right)$, and space cooling $\left(E P_{C}\right)$ are calculated in $B Q E$ but they are omitted here, since they are substantially independent from the selected alternatives. Besides, the energy perfor- 
mance index for space cooling $\left(\mathrm{EP}_{\mathrm{C}}\right)$ is not significant because air systems are not considered, neither airsource heat pumps powered by electricity from PV.

In figure 2 the dotted lines represent the boundaries of the coloured areas that highlight the range of both $\mathrm{EP}_{\mathrm{H}}$ and intervention costs for each building. Building no. 3 "Albertoni" shows the widest range of improvement, as $\mathrm{EP}_{\mathrm{H}}$ value can be improved from $255.95 \mathrm{kWh} / \mathrm{m}^{2} \mathrm{y}$ to $95,88 \mathrm{kWh} / \mathrm{m}^{2} \mathrm{y}$ (intervention number 12). Instead, the performance of the building No. 1 "Lercaro" has the smallest range of improvement, from 114.30 $\mathrm{kWh} / \mathrm{m}^{2} \mathrm{y}$ to $64.67 \mathrm{kWh} / \mathrm{m}^{2} \mathrm{y}$, but shows the widest variation of intervention costs, because the initial level was already good. Therefore, the chart displayed in figure 2 allows the energy manager to find quickly the building with the most cost-effective intervention, depending on the goal: reaching the nZEB standard (case study No. 1), maintaining the cost of intervention under a certain value (search for minimum cost, cases No. 2 and No. 3), or obtaining the highest percentage of energy savings (cases No. 2 and No. 3).

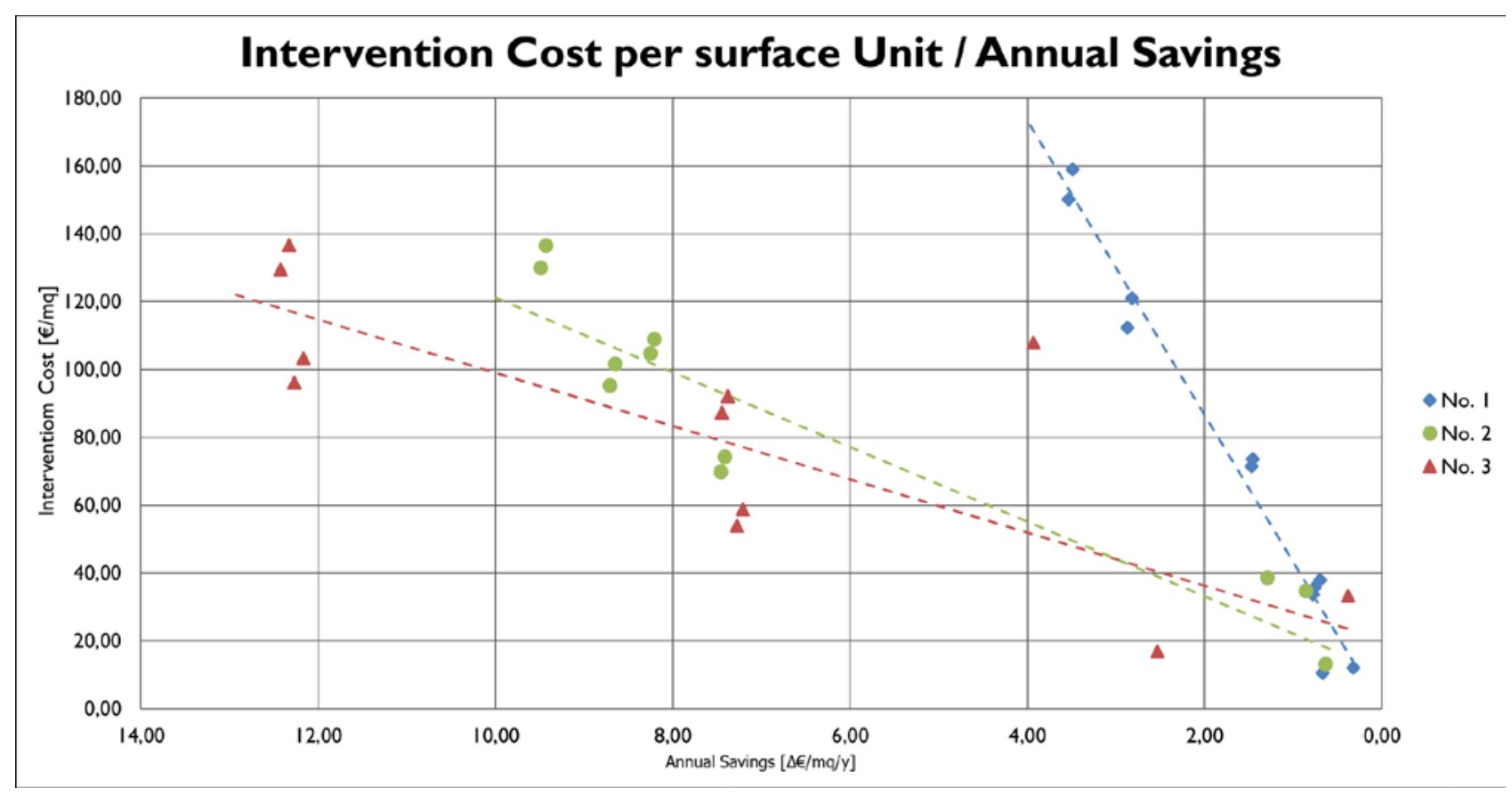

Fig. 6. Intervention Cost per surface Unit (ICu) and energy costs in the three buildings over a study period of 30 years.

Many interventions appear to be more suitable for two buildings ("Albertoni" and "San Nicolò di Mira") in comparison to the "Lercaro" building, which requires high costs for a small energy improvement. It is also worth noticing that there is a substantial linearity between the costs of the intervention and the final energy performance; besides, only the interventions on both the opaque and the transparent parts of the entire envelope allow to reach the minimum required overall nZEB performance levels. As long as renewable energy sources are not employed, the performance of all the interventions is, in most cases, far from reaching the 
standard of zero net energy consumption. In conclusion, in order to reach the nearly zero target, a significant percentage of energy should always be provided by renewable sources. Renewable resources energy can be produced on-site, likely on the roof of the buildings with PV systems. According to Italian energy standards, a target of at least $2 \mathrm{KW}$ of electricity every $100 \mathrm{~m}^{2}$ of usable surface, should be produced. Along with the installation of heat pumps, PV systems will bring down the calculated EP by approximately $40 \%$, reaching the goals of nZEBs according to national regulations (class A4-A1).

On a slightly different perspective, if the goal of energy retrofitting project is the shortest PBP, the most convenient interventions are characterized by the minimum ratio between initial costs and obtainable savings during the first year of operation; therefore, the initial convenience is represented by the ratio $€ / \mathrm{kWh} / \mathrm{y}$ (where $y=1)$. In fact, relating the initial cost $\left(€ / \mathrm{m}^{2}\right)$ and the obtained annual savings (due to annual heating energy costs) it is possible to obtain an evaluation of the simple PBP (y), ignoring the time value of money. This can be evaluated through the slope of the lines plotted in the chart of (fig. 6) where the annual savings are reported on the x-axis and the initial cost (per surface unit) are plotted on the $y$ - axis. Dashed lines show the trend due to the increase of annual savings related to intervention cost augmentation.

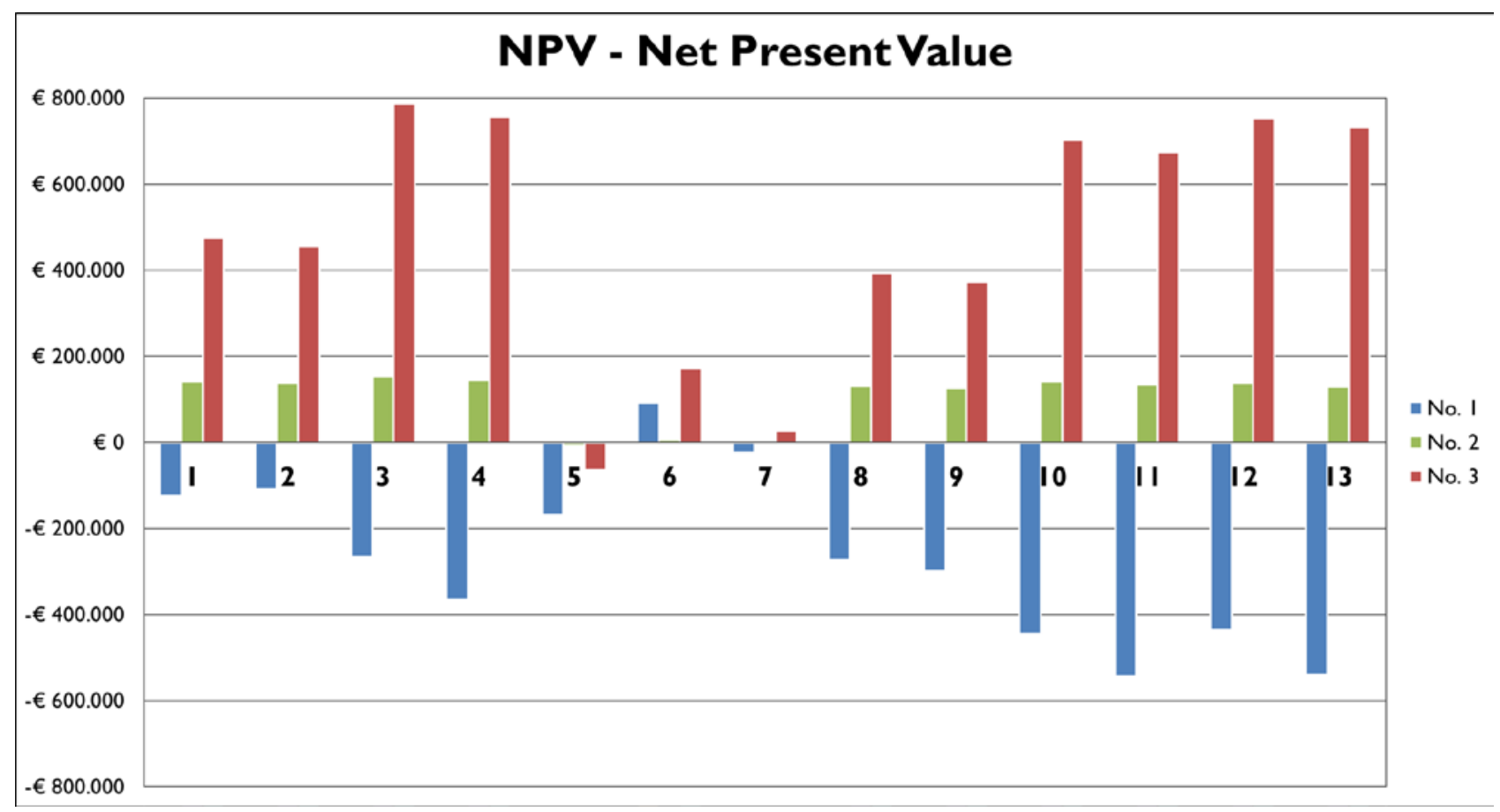

Fig. 7. NPV value of the set of thirteen retrofitting interventions.

The cost optimal interventions are the ones plotted by the lines with a smaller slope. Again, in the "Lercaro" No. 1 building energy renovation projects have the lowest yearly savings. This result was predictable, since the building is the newest one, and in fairly good conditions, but is the only one that can reach the nZEB tar- 
get with the better four proposed intervention (fig. 8). In fact, the negative values of NPV over a period of 30 years for the building no. 1 "Lercaro" confirm the tendencies of the payback period (fig. 7) as only the intervention no.6 (condensing boiler replacement) has a positive NPV value.

Energy retrofitting interventions are mostly convenient for a building with a very poor energy performance. Besides, these interventions should take into consideration at least the whole envelope, rather than focusing only on the facades and the opaque surfaces. These are the cases of building no. 2 "Mira" and no.3 "Albertoni" where the best NPV value is the one of the intervention no. 3 (thermal insulation of entire envelope) as shown in figure 4. Similar results are achieved considering the GC of the interventions related to energy performance. Energy performance of each building can be plotted against global cost in a $E P_{H}-G C$ chart, where $\mathrm{EP}_{\mathrm{H}}$ is plotted on the $\mathrm{x}$-axis and $\mathrm{GC}$ for a study period of 10,20 and 30 years is plotted on the $y$-axis (fig. 6-7-8). Therefore, the $\mathrm{EP}_{\mathrm{H}}-\mathrm{GC}$ charts show the different behaviours of the case study buildings. In the case of building no. 1 "Lercaro" GC increases with the increase of energy performance, i.e. with the decrease of $\mathrm{EP}_{\mathrm{H}}$ (fig. 8).

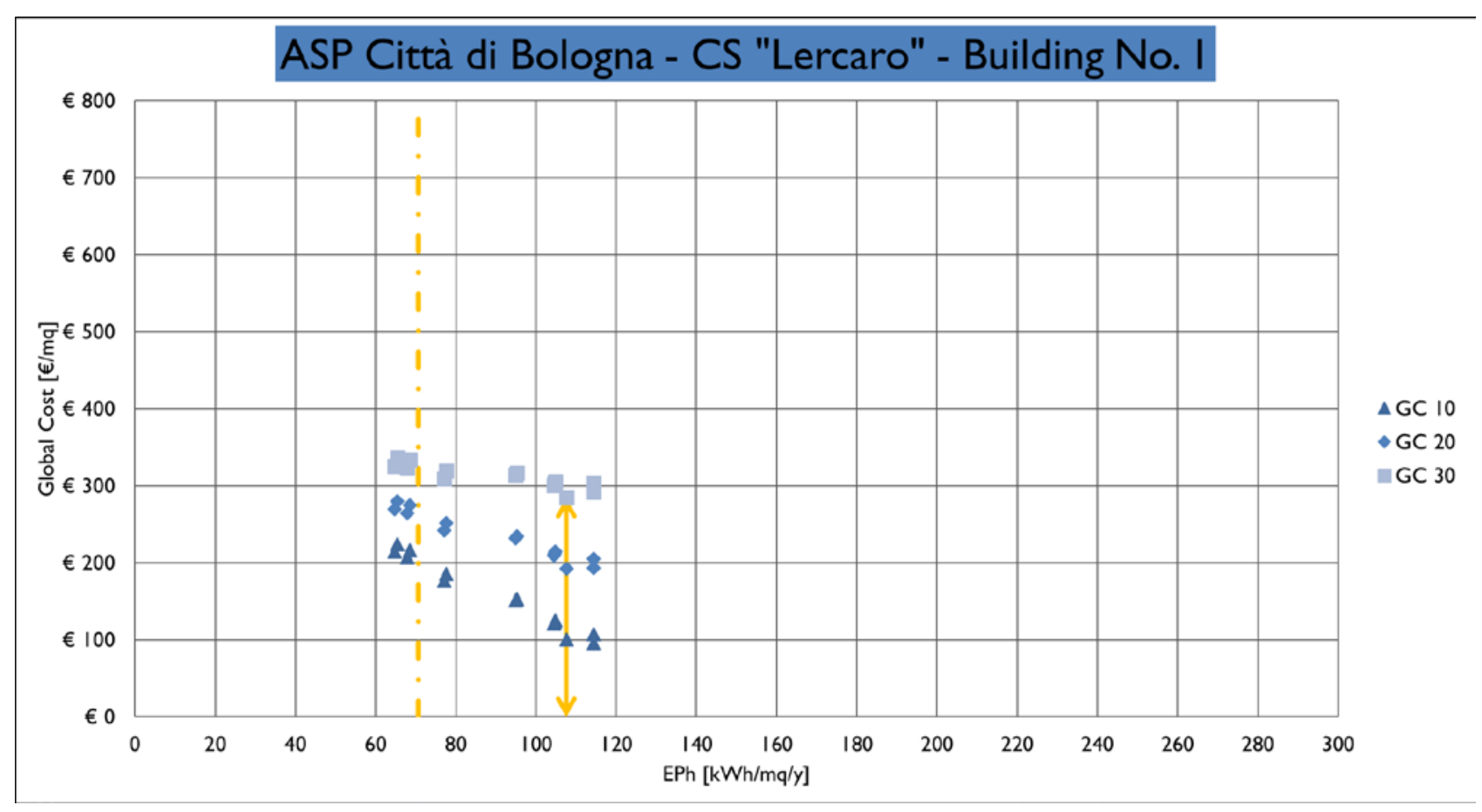

Fig. 8. Global cost and energy performance index for space heating $\left(\mathrm{EP}_{\mathrm{H}}\right)$ of building no. 1 "Lercaro", compared to reference building with nZEBs values (vertical dotdash line). 


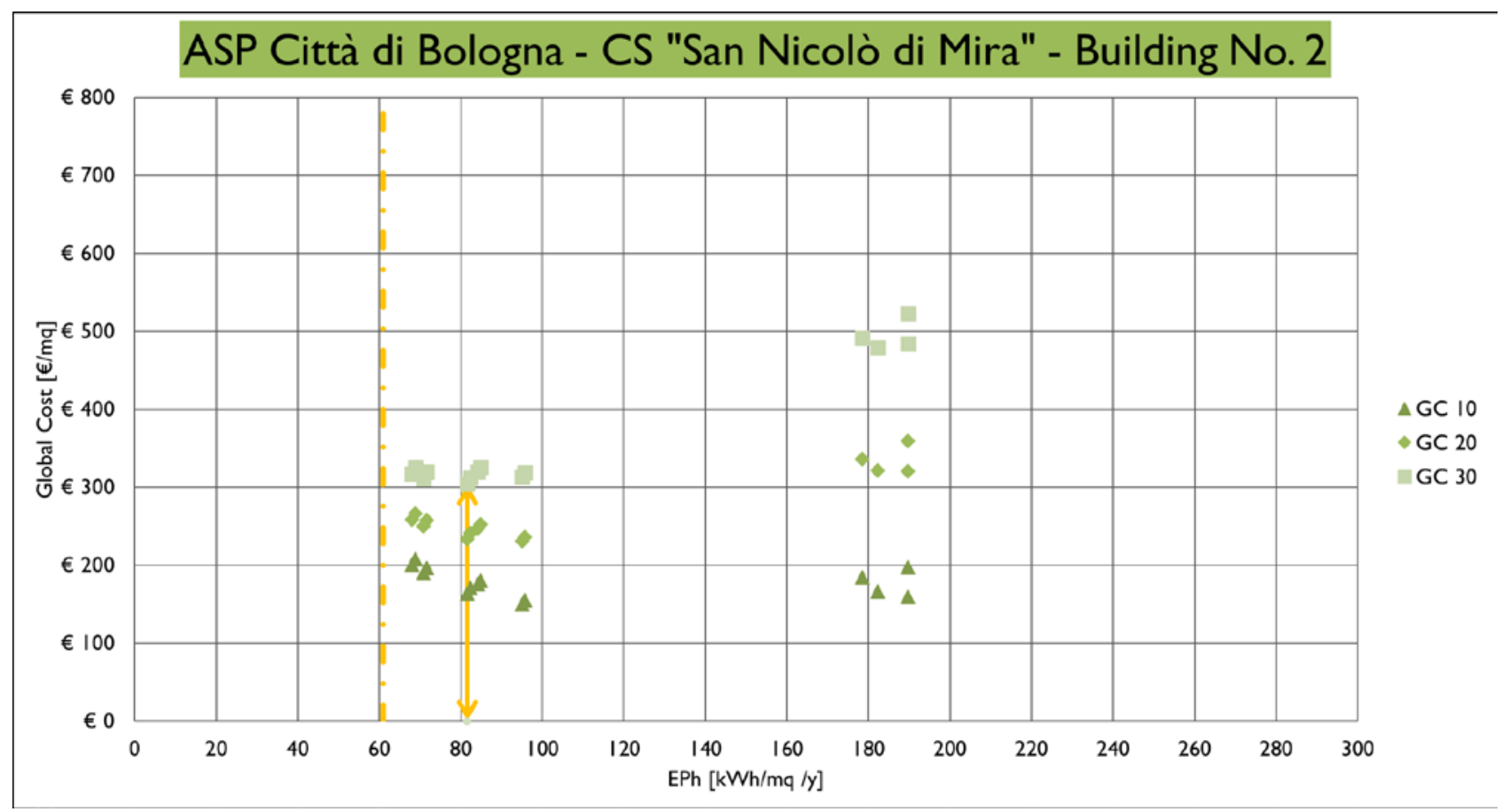

Fig. 9. Global cost (GC) and energy performance index for space heating $\left(E P_{H}\right)$ of building no. 2 "San Nicolò di Mira", compared to reference building with nZEBs values (vertical dotdash line).

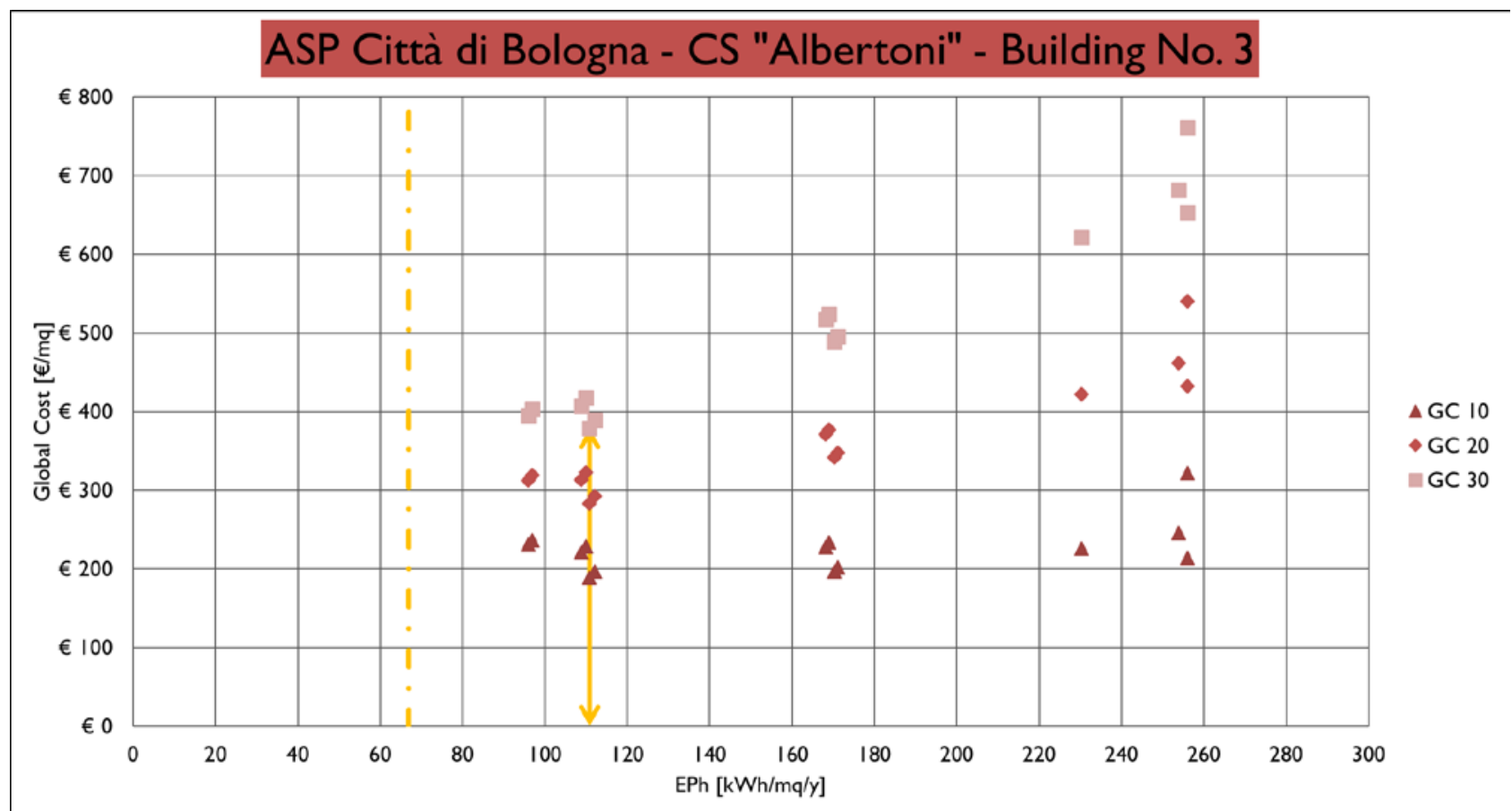

Fig. 10. Global cost (GC) and energy performance index for space heating $\left(\mathrm{EP}_{\mathrm{H}}\right)$ of building no. 3 "Albertoni", compared to reference building with nZEBs values (vertical dotdash line).

Instead, in buildings no. 2 "Mira" and no. 3 "Albertoni" (fig. 9-10) GC decreases with the rise of the energy performance, depending on the increase of the study period from 10 year to 30 years. In these $\mathrm{EP}_{\mathrm{h}}-\mathrm{GC}$ charts, the yellow arrow indicates the most convenient alternative as estimated with the 30 years GC. The distance between the yellow arrow and dash-dot line (representing the $E P_{H}$ reference value for nZEB), indi- 
cates how far the nZEB target from the most convenient combination of interventions is. Besides, in order to reach the nZEB goal for the "Lercaro" building, which is the only case where it is possible to reach that goal with these standard solutions, it is necessary to double the global costs over ten years.

A sensitivity analysis was finally performed to show the impact of energy price escalation rates on costoptimal results. The analysis showed that an increase of the energy rate from 3,3 to 4,3\% would reduce the PBP by $10-25 \%$, depending on the retrofit alternative. This increase should stimulate combinations with higher initial costs.

All these results of the DSS were presented to the decision makers of the company for the selection of the renovation strategies to be implemented in the case study buildings.

\section{Conclusions}

Large real estate companies may demonstrate some hesitation in defining the best strategy for the energy retrofitting of their building stock. A DSS entailing a cost-optimal approach has been proposed to optimize design choices. The proposed method focuses on major energy renovation alternatives with the aim of reaching nZEB standards, given the assumption that interventions take place only when social and political conditions are favourable. The evaluation of the most advantageous intervention to be performed on a built asset (i.e. the maximum possible saving during a reference service life of a building) and the cost-optimal renovation solution (i.e. the most sustainable solution that reaches the renovation potential) can be assessed through the NPV evaluation of initial and energy costs, along with the GC assessment. A better estimate can be developed matching together NPV and GC with energy performance indicators, like the $\mathrm{EP}_{\mathrm{H}}$ value.

In the event that the economic optimum does not deliver sufficient guidance to reach such nZEB targets, the proposed method is robust enough to be used as a transparent steering tool to improve framework conditions in order to "push" the economic optimum towards the point that it will meet environmental and societal targets. The optimum towards even more ambitious environmental levels could be achieved with macroeconomic instruments, e.g. reduced interest rates, direct support, loan guarantees, inclusion of $\mathrm{CO}_{2}$-price in energy costs, cost reductions (economies of scale), performance and productivity improvements (learning curves).

The cost-optimal approach introduced by the EU global cost method, implemented with the NPV related to the $\mathrm{EP}_{\mathrm{H}}$ values, demonstrated to be efficient enough to establish the renovation potential of a building and/or a built asset over a long period. The sensitivity analysis performed increasing the study period for the GC 
evaluation from 10 years to 20 and 30 years pointed out that the expected increase of energy costs in the next future and the length of the study period are the most important factors to determine different scenarios. On the other hand, as long as the presented method is a cost-parametric evaluation of different design solutions and the evaluation is performed through the comparison of different cases with the same economical input data, the choice of the best solution can be considered robust enough in terms of variations of economical parameters.

A few considerations on environmental and social aspects should be addressed for future research work, as it is believed that $\mathrm{CO}_{2}$ emissions are not adequately considered in a sustainability perspective. In fact, the cumulated carbon cost of a building system in the operation phase is calculated by taking the sum of the annual greenhouse gas emissions multiplied by the minimum price of EUR 20 per tonne of $\mathrm{CO}_{2}$ equivalent until 2025, EUR 35 until 2030 and EUR 50 beyond 2030. For natural gas, this is the same of saying $20 \times 490 \times$ $10^{-6} \mathrm{EUR} / \mathrm{kWh}$. This is equivalent to $0,0098 \mathrm{EUR} / \mathrm{kWh}$, which appears to be a rather small percentage (less than 1 eurocent per kWh), compared to standard energy running costs. Maintenance costs should be accurately addressed as well, even if they can slightly affect NPV calculation, since energy costs are the main drivers of the economic evaluation in the study period.

\section{References}

[1] A. Ferrante, G. Semprini, Energy retrofitting in urban areas, Procedia Engineering 21 (2011) 968-975.

[2] S. Lechtenböhmer S, A. Schüring, The potential for large scale savings from insulating residential buildings in the EU, Energy efficiency 4 (2) (2009) 257-270.

[3] M.A. Bragadin, L. Boiardi, L. Santoni, Global Cost Analysis for energy refurbishment of Social Housing, ISTEA 2014 Proceedings, Maggioli, Rimini, 2014.

[4] J. Kurnitski, F. Allard, D. Braham, G. Goeders, P. Heiselberg, L. Jagemar, R. Kosonen, J. Lebrun, L. Mazzarella, J. Railio, O. Seppänen, M. Schmidt, M. Virta, How to define nearly net zero energy buildings nZEB - REHVA proposal for uniformed national implementation of EPBD recast, Rehva Journal (2011) 6-12.

[5] US Department of Energy, A Common Definition for Zero Energy Buildings, September 2015.

[6] R. Hoogmartens, S. Van Passel, K. Van Acker, M. Dubois, Bridging the gap between LCA, LCC and CBA as sustainability assessment tools, Environmental Impact assessment review 48 (2014) 27-33.

[7] A. Mickaityte, E.K. Zavadskas, A. Kaklauskas, L. Tupenaite, The concept model of sustainable building refurbishment, International Journal of Strategic Property Management, 12 (1) (2008) 53-68.

[8] E. De Angelis, G. Pansa, E. Serra, Research of economic sustainability of different energy refurbishment strategies for an apartment block building, SHC 2013, International Conference proceedings, Energy Procedia 48 (2014) 1449-1458.

[9] G. Pansa, E. De Angelis, Cost-optimal analysis of building renovation strategies and the assessment of the "renovation potential" of a built asset, Tema1 (2) (2015) 112-117. 
[10] Directive 2010/31/EU of the European Parliament and of the Council of 19 May 2010 on the energy performance of buildings (recast).

[11] EST (Energy Saving Trust). Using whole life cycle costing as a basis for investments in energy efficiency - guidance (2005 edition).

[12] Commissioning delegated regulation (EU) No 244/2012 of 16 January 2012.

[13] A. Famuyibo, A. Duffy, P. Strachan, Achieving a holistic view of the life cycle performance of existing dwellings, Building and Environment 70 (2013) 90-101.

[14] IPCC, Climate Change 2014: Synthesis Report. Contribution of Working Groups I, II and III to the Fifth Assessment Report of the Intergovernmental Panel on Climate Change [Core Writing Team, R.K. Pachauri and L.A. Meyer (Eds.)]. IPCC, Geneva, Switzerland, 151 pp., 2014.

[15] EN 15459, Energy performance of buildings: economic evaluation procedure for energy system in buildings, 2008.

[16] T. Boermans, J. Grözinger, B. von Manteuffel, N. Surmeli-Anac, J. Ashok, K. Leutgöb, D. Bachner, Assessement of Cost Optimal calculations in the context of EPBD (ENER/C3/2013/414). Final report, Ecofys, 2015.

[17] N.G. Sağlam, A.Z. Yilmaz, C. Becchio, S. P. Corgnati, A comprehensive cost-optimal approach for energy retrofit of existing multi-family buildings: Application to apartment blocks in Turkey, Energy and Buildings, 150 (2017) 224-238.

[18] M. Hamdy, A. Hasan A., K. Siren, A multi-stage optimization method for cost-optimal and nearly-zero energy building solutions in line with the EPBD-recast 2010, Energy and Buildings, 56 (2013) 189-203.

[19] R. Ruparathna, K. Hewage, R. Sadiq, Economic evaluation of building energy retrofits: a fuzzy based approach, Energy and Buildings 139 (2017) 395-406.

[20] E. Di Giuseppe, A. Massi, M. D'Orazio, Impacts of Uncertainties in Life Cycle Cost Analysis of Buildings Energy Efficiency Measures: Application to a Case Study, Energy Procedia 111 (2017) 442-451.

[21] P. Congedo, D. D'Agostino, C. Baglivo, G. Tornese, I. Zacà, Efficient solutions and cost-optimal analysis for existing school buildings, Energies 9 (2016) 851.

[22] I. Zacà, D. D'agostino, P. Congedo, C. Baglivo, Assessment of cost-optimality and technical solutions in high performance multi residential buildings in the Mediterranean area, Energy and Buildings 102 (2015) 250-265.

[23] E. Pikas, M. Thalfeldt, J. Kurnitski, Cost optimal and nearly zero energy building solutions for office buildings, Energy and Buildings 74 (2014) 3042.

[24] J. Kurnitski, A. Saari, T. Kalamees, M. Vuolle, J. Niemela, T. Tark, Cost Optimal and near zero (nZEB) energy performance calculations for residential buildings with REHVA definition of nZEB national implementation, Energy and Buildings 43 (2011) 3279-3288.

[25] M. Ferreira, M. Almeida, A. Rodrigues, Cost Optimal energy efficiency level are the first step in achieving cost effective renovation in residential buildings with a nearly zero energy target, Energy and Buildings 133 (2016) 724-737.

[26] I. Sartori I, A. Hestnes, Energy use in the life cycle of conventional and low energy buildings: a review article. Energy Build,39 (2007) 249-57.

[27] J. Clinch, J. Healy, C. King, Modelling improvements in domestic energy efficiency. Environ Modell Softw 16 (2001) 87-106. 
[28] D.M. of June 26th, 2015, "Applicazione delle metodologie di calcolo delle prestazioni energetiche e definizione delle prescrizioni e dei requisiti minimi degli edifici".

[29] N. Bartolini, F. Della Fornace F, R. Gulli, C. Mazzoli, D. Prati, Misurare la qualità complessiva degli edifici. II protocollo BQE (Building Quality Evaluation), Colloqui.AT.e 2015 - L'evoluzione del sapere in Architettura Tecnica, 2, Maggioli, Milano, 2016.

[30] ISO 13790:2008, "Energy performance of buildings - Calculation of energy use for space heating and cooling".

[31] UNI TS 11300 1-4 2008-2014 "Prestazioni energetiche degli edifici".

[32] D.Lgs. of August 19th, 2005, no.192, "Attuazione della direttiva 2002/91/CE relativa al rendimento energetico nell'edilizia"

[33] D.Lgs. of December 29th, 2006, no. 311, "Disposizioni correttive ed integrative al decreto legislativo 19 agosto 2005, no. 192, recante attuazione della direttiva 2002/91/CE, relativa al rendimento energetico nell'edilizia".

[34]BPIE, Nearly Zero Energy Buildins Definition across Europe, available at http://bpie.eu/uploads/lib/document/attachment/128/BPIE factsheet nZEB definitions across Europe.p df (accessed 18.05.2017) 